Original article

\title{
Clopidogrel and the possibility of drug-drug interaction in primary health care
}

\author{
Inga Urtane*, Aleksandra Aitullina, Katrina Pukite \\ Department of Pharmacy, Riga Stradiņš University, Latvia
}

\section{A R T I C L E I N F O}

\section{Article history:}

Received 20 October 2012

Accepted 13 December 2012

Available online 7 March 2013

\section{Keywords:}

Amlodipine

Atorvastatin

Clopidogrel

Drug-drug interaction

Omeprazole

\begin{abstract}
A B S T R A C T
Introduction: Clopidogrel ineffectiveness is a serious problem in antiplatelet therapy. Many factors may contribute to this phenomenon. One of them is clopidogrel drug-drug interaction with CYP2C19 and CYP3A4 enzyme inhibitors. The main goal of this descriptive study was to assess the prevalence of cases of clopidogrel-drug interactions in the primary health care physicians' practices.

Materials and methods: During 2010-2011, 80 patients receiving clopidogrel antiplatelet therapy from primary care physicians' clinical practices were involved in this study. By using questionnaires and case histories, the following information was collected: Age, gender, clinical diagnoses, and medications used. Results: In the current study, drugs were used that could potentially influence the effect of clopidogrel: Omeprazole, lipophilic statins, calcium channel blockers (CCB). There was a different use of the abovementioned drugs before and after the initiation of the clopidogrel therapy, e.g., $12(15.0 \%)$ and 44 (55.0\%) patients used proton pump inhibitors (PPI) before and after the clopidogrel therapy accordingly $\left(P=0.16 ; \chi^{2}=1.91\right)$. However, pantoprazole was recommended more often than other PPI. The use of the potential CYP3A4 inhibitors - lipophilic statins and CCB - was increased after the prescription of clopidogrel too. Concomitant use of statins (mainly atorvastatin) with clopidogrel was observed in 75 (93.8\%) patients and the use of CCB (mainly amlodipine) - in 33 (41.3\%) patients.

Conclusion: In the primary health care practices, it is revealed that there is co-medication of clopidogrel with weak CYP3A4 inhibitors, such as lipophilic statins and amlodipine, and with the moderate CYP2C19 inhibitor - omeprazole. The latter co-medication is potentially harmful and it is very important to inform the first care professionals about the opportunity to change omeprazole to pantoprazole, which does not influence clopidogrel biotransformation.
\end{abstract}

Copyright @ 2013, InPharm Association, Published by Reed Elsevier India Pvt. Ltd. All rights reserved.

\section{Introduction}

Clopidogrel is widely used as a thienopyridine antiplatelet agent, which irreversibly inhibits the adenosine di-phosphatedependent pathway of platelet activation. ${ }^{1}$ The aspirin and clopidogrel combination becomes the gold standard for preventing cardiovascular events in high-risk patients in the development of thrombosis. $^{2}$

Data of several clinical researches show that clopidogrel therapy is not effective enough for a part of the patients. ${ }^{3}$ It is supposed that the reason behind this phenomenon is multi-factorial, so it is important to analyze many factors and their interaction. The first step that may be taken to increase the effectiveness of this therapy is to study the prevalence of factors that may contribute to a decrease of the antiplatelet effect in patients receiving clopidogrel. Some of the possible factors are pharmacogenetic, chronic

\footnotetext{
* Corresponding author.

E-mail address: inga_ut@inbox.lv (I. Urtane).
}

diseases (e.g., diabetes mellitus) and drug-drug interactions. ${ }^{2}$ The first two factors are not modifiable and it is possible that this group of patients should receive other antiplatelet therapy or clopidogrel at the increased dose $(150 \mathrm{mg} /$ daily instead of $75 \mathrm{mg} /$ daily $) .{ }^{4}$ The last factor from the above-mentioned list is modifiable, so it may be avoided, if medical professionals pay more attention to it.

Drug-drug interactions are mainly studied from a pharmacokinetic aspect, because there is an assumption that the most common cause of alteration of the expected effect of drug is connected with inhibition or induction of the cytochrome P (CYP) 450 enzymes that have participated in the drug biotransformation. ${ }^{5}$ The pharmacokinetics of clopidogrel is being widely studied now. Recent research shows, that the main liver microsomal enzymes, involved in clopidogrel biotransformation to its active metabolite, are CYP2C19 and CYP3A4. ${ }^{6,7}$ They are principal enzymes in the metabolism of proton pump inhibitors (PPI), statins and calcium channel blockers (CCB). ${ }^{7}$ Concomitant use of the drugs reduces the clopidogrel active metabolite concentration in plasma and antithrombotic effect by competitive mechanism [Fig. 1]. 

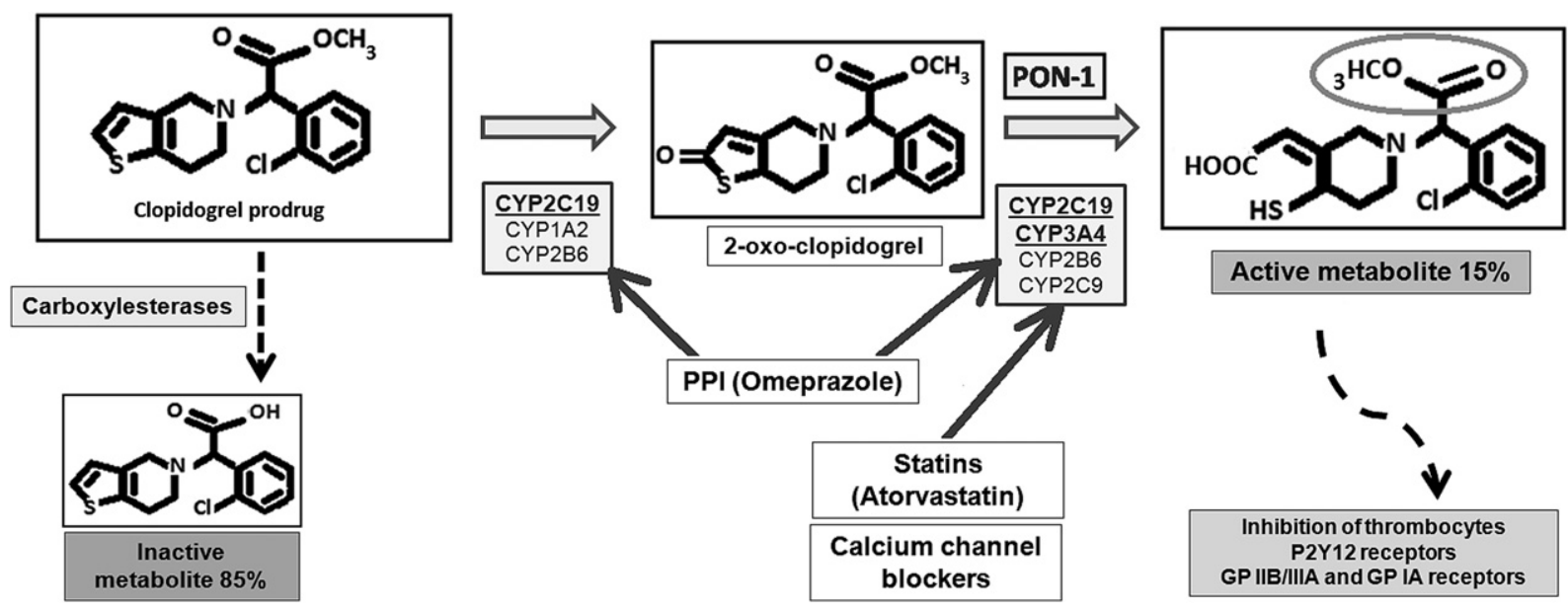

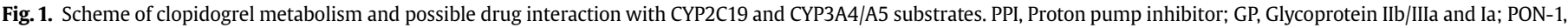
Paraoxonase-1; CYP, Cytochrome P450 enzymes.

The main goal of this descriptive study was to assess the prevalence of cases of clopidogrel-drug interactions in the primary health care physicians' practices and to analyze the possibility for the reduction of this potential factor of clopidogrel ineffectiveness.

\section{Materials and methods}

In this retrospective descriptive study, 80 patients were involved from the first care physicians' clinical practices, receiving clopidogrel antiplatelet therapy in Latvia, Riga, during 2010-2011. Using questionnaires and case histories the following information was collected: Age, gender, clinical diagnoses, and medications used before and after the first prescription of clopidogrel. The main reason for the administration of clopidogrel in the current study was to state how to prevent the occurrence of cardiovascular events after percutaneous coronary intervention (PCI). Potential CYP2C19 and/or CYP3A4/A5 inhibitors were selected from the co-medications of clopidogrel. Data were analyzed using Statistical Package for the Social Sciences (SPSS Statistics) 17.0. Qualitative variables were compared using the Pearson Chi-Square test. The main results were reported as well as the SD or number and percentage as appropriate. A $P$ value $<0.05$ was considered to be significant.

\section{Results}

Information about the baseline characteristics of the patients is summarized in Table 1 .

Table 1

Baseline characteristics of 80 patients.

\begin{tabular}{ll}
\hline Characteristics $(n=80)$ & Results \\
\hline Median age & $63 \pm 10$ \\
Male (\%) & $48(60.0)$ \\
Median body weight $(\mathrm{kg})$ & $85 \pm 16$ \\
Cardiovascular risk factor & \\
Smoking (\%) & $10(12.5)$ \\
Ex-smoker (\%) & $35(43.8)$ \\
Never smoked (\%) & $34(42.5)$ \\
Hypertension (\%) & $64(80.0)$ \\
Diabetes mellitus (\%) & $22(27.5)$ \\
Clinical diagnose & \\
MI (\%) & $23(28.8)$ \\
Congestive heart failure (\%) & $51(63.8)$ \\
Stroke (\%) & $6(7.5)$ \\
Unstable angina (\%) & $9(11.3)$ \\
\hline
\end{tabular}

MI, Myocardial infarction.
In the current study, $48(60.0 \%)$ men at a medium age $( \pm S D)$ of $60.94 \pm 10.01$ and $32(40.0 \%)$ women at a medium age \pm SD of $66.13 \pm 9.10$ were enrolled. Using the independent-samples $t$ test, it was concluded that the mean age of women and men is statistically different $(t=2.35 ; P=0.02)$.

The analysis of PPI used before and after the first prescription of clopidogrel presented that before clopidogrel therapy only 12 (16.7\%) patients had received treatment with PPI and 9 (12.5\%) of them continued the above-mentioned therapy after starting the use of clopidogrel. Sixty (83.3\%) patients, in turn, did not use PPI before clopidogrel therapy and 32 (44.4\%) patients from this group started to use PPI after the prescription of clopidogrel. Approximately one-third of the study participants (28 (38.9\%) patients) did not use PPI at all. PPI types are summarized in Table 2 . The Pearson Chi-Square analysis reveals that there is no statistical significance between the use of PPI before and after the initiation of clopidogrel therapy $\left(P=0.16 ; \chi^{2}=1.91\right)$.

The use of the potential CYP3A4 inhibitors - lipophilic statins and $\mathrm{CCB}$ - was increased after PCI and accordingly after the prescription of clopidogrel. Concomitant use of statins (mainly atorvastatin) with clopidogrel was revealed in 75 (93.8\%) patients and the use of CCB (mainly amlodipine) - in 33 (41.3\%) patients. Concomitant use of CYP3A4 and CYP2C19 inhibitors among study participants is summarized in Table 3.

\section{Discussion}

Nowadays, there are a lot of studies on clopidogrel drug-drug interactions as there is an opinion that it may be a potential

Table 2

Administration of medications before and after percutaneous coronary intervention.

\begin{tabular}{lll}
\hline Medications & $\begin{array}{l}\text { Medication administered } \\
\text { before PCI }(\%)\end{array}$ & $\begin{array}{l}\text { Medication administered } \\
\text { after PCI }(\%)\end{array}$ \\
\hline $\begin{array}{l}\text { Clopidogrel }(n[\%]) \\
\text { Aspirin }(n[\%])\end{array}$ & - & $80(100.0)$ \\
$\begin{array}{l}\text { Statin (mainly } \\
\text { atorvastatin; } n[\%])\end{array}$ & $51(63.8)$ & $75(93.8)$ \\
CCB (mainly & $24(30.0)$ & $75(93.8)$ \\
$\quad$ amlodipine; $n[\%])$ & & $33(41.3)$ \\
PPI ( $n$ [\%]) & $12(15.0)$ & $44(55.0)$ \\
Esomeprazole & - & $1(2.2)$ \\
Pantoprazole & $6(7.5)$ & $23(52.2)$ \\
Omeprazole & $6(7.5)$ & $20(45.4)$ \\
\hline
\end{tabular}

PCI, Percutaneous coronary intervention; CCB, Calcium channel blockers; PPI, Proton pump inhibitors. 
Table 3

Cytochrome P3A4 and cytochrome P2C19 inhibitors use among patients receiving clopidogrel antiplatelet therapy.

\begin{tabular}{|c|c|c|c|c|c|}
\hline \multirow[t]{2}{*}{ Used medications } & \multicolumn{3}{|l|}{ PPI type } & \multirow{2}{*}{$\begin{array}{l}\text { Lipophilic statin } \\
\text { (atorvastatin) (\%) }\end{array}$} & \multirow{2}{*}{$\begin{array}{l}\text { CCB (amlodipine) } \\
(\%)^{*}\end{array}$} \\
\hline & Esomeprazole (\%) & Omeprazole (\%) & Pantoprazole (\%) & & \\
\hline CCB (amlodipine) & - & $9(11.2)$ & $7(8.7)$ & $33(41.5)$ & - \\
\hline Lipophilic statin (atorvastatin) & $1(1.2)$ & $19(23.7)$ & $23(28.7)$ & - & $33(41.5)$ \\
\hline
\end{tabular}

*Percentage is calculated from whole amount of participants $(n=80)$, CCB, Calcium channel blocker; PPI, Proton pump inhibitor.

factor of ineffectiveness of antiplatelet therapy. The clopidogreldrug interactions that were examined in the current study are often reported in other studies too, because co-administration of these drugs with clopidogrel is clinically rational.

\subsection{Clopidogrel and omeprazole co-medication}

PPI co-administration with clopidogrel decreases gastrointestinal bleeding events. ${ }^{8}$ It is not recommended to stop PPIs administration during antiplatelet dual therapy. Despite it, there are many reports about the influence of omeprazole on clopidogrel biotransformation that may result in an increased clopidogrel nonresponders rate. ${ }^{9}$ The US Food and Drug Administration (FDA) has issued a warning about the interaction of clopidogrel and omeprazole. ${ }^{10}$ Omeprazole reduces the antiplatelet effect of clopidogrel by about $50.0 \%$. There has been a hypothesis, that since omeprazole is rapidly cleared, the interaction could be mitigated in the case where clopidogrel and omeprazole doses are administrated $12 \mathrm{~h}$ apart. However, data suggest that omeprazole is a time-dependent, irreversible inhibitor of CYP2C19. This may explain the similar levels of interaction observed, whether clopidogrel and omeprazole were administered simultaneously or $12 \mathrm{~h}$ apart. ${ }^{11}$ In the situation where it is not advisable to cancel some drug from the individual plan of pharmacotherapy, it is important to change this to its pharmacological alternative. The results of some clinical studies show that the best alternative for omeprazole, which is the moderate CYP2C19 inhibitor, is pantoprazole which seems to have much lower potential to inhibit CYP2C19. ${ }^{12}$ In the current study, pantoprazole was recommended more often in comparison to other PPIs available, while some patients had not received omeprazole therapy yet.

\subsection{Clopidogrel and calcium channel blockers co-medication}

Statins and CCB are widely used in cardiology and the possibility of their co-medication with clopidogrel is very high. In our study these data were confirmed - the majority of patients received clopidogrel with lipophilic statins, CCB or both. In the last few years a lot of studies have been published with an aim to check the clinical relevance of these drug-drug interactions, although no evident results have been received yet.

In some studies, the concomitant use of CCB and clopidogrel was associated with decreased platelet inhibition by clopidogrel. ${ }^{13,14}$ But in other studies, this hypothesis was not confirmed and in these cases, no evidence was found that CCB could decrease the efficacy of antiplatelet therapy. ${ }^{15-17}$ In one recent study, a poor-response of clopidogrel was associated with amlodipine use, but not with other CCB use. It can possibly be explained by another CCB ability to inhibit P-glycoprotein, a transporter that can decrease clopidogrel absorption from the intestinal tract. Amlodipine does not inhibit this protein and possibly does not influence clopidogrel absorption. ${ }^{18}$ To prove this hypothesis, it is necessary to carry out further investigations.

\subsection{Clopidogrel and lipophilic statins co-medication}

In one recent study, conducted in vitro, it was investigated how different types of CYP inhibitors can influence biotransformation and the antiplatelet effect of clopidogrel. These experiments revealed that inhibitors for both main enzymes involved in clopidogrel biotransformation - CYP3A4 and CYP2C19 - could decrease the formation of the active metabolite of clopidogrel. Strong CYP3A4 inhibitors, such as ketoconazole and clarithromycin, showed a stronger inhibitory effect than lipophilic statins. In addition, the inhibition of clopidogrel biotransformation and impaired antiplatelet effect by simvastatin or atorvastatin was revealed to be dose-dependent. Moreover, simvastatin was shown to be a stronger inhibitor than atorvastatin. ${ }^{19}$ This finding can be explained by the difference in the chemical structure of simvastatin and atorvastatin. Simvastatin is a lactone pro-drug, which is metabolized by the enzyme more rapidly than atorvastatin, which is in an acid form. ${ }^{20}$

Dose-dependent atorvastatin inhibitory effect on clopidogrel biotransformation was shown in an ex vivo experiment by Lau et al. $^{21}$ In one later study about the influence of statin on the clopidogrel antiplatelet effect in vivo, it was revealed that the interference between statins and clopidogrel was best seen during the loading phase $(5 \mathrm{~h})$, but in the maintenance phase ( $48 \mathrm{~h}$ ) it was marginal, although still significant. ${ }^{22}$

Although the experimental data in vitro and ex vivo showed that statins can influence clopidogrel biotransformation, these results cannot be directly integrated into clinical practice. Nowadays, there are no statistically significant results about the influence of statin on clopidogrel therapy in different clinical studies. $^{23,24}$ The main limitations of these studies were as follows: Statin dose in the study population was quite low, a few participants used non-CYP3A4-metabolized statins in comparison to CYP3A4-metabolized statin users, these studies were retrospective. ${ }^{24}$ Rosuvastatin, that has no influence on the CYP3A4 system, can be a good alternative instead of a high dose of atorvastatin in patients with clopidogrel therapy and for the high-risk patients in developing cardiovascular events.

\section{Conclusion}

In the current study, the potentially undesirable effects of clopidogrel combination with the CYP2C19 inhibitor PPI (omeprazole) and CYP3A4/A5 inhibitors statins (mainly atorvastatin) and CCB (mainly amlodipine) have been revealed. Moreover, $20.0 \%$ of the patients received all the three above-mentioned medications at the same time. PPIs administration increases by almost 4 times for patients with clopidogrel therapy in comparison to the time before, 12 (15.0\%) versus 44 (55\%), respectively. The main reason for PPI administration could be the decrease of risk of gastrointestinal bleeding that might occur during dual antiplatelet therapy. The alternative for omeprazole could be pantoprazole which affects clopidogrel biotransformation to a lesser extent. It could be beneficial for a lot of patients if doctors and pharmacists would use this information in their routine practice.

\section{Conflicts of interest}

All authors have none to declare. 


\section{References}

1. Armstrong AW, Golan DE. Pharmacology of hemostasis and thrombosis. In: Golan DE, Tashjian AH, eds. Principles of Pharmacology: The Pathophysiologic Basis of Drug Therapy. 3rd ed. Philadelphia: Lippincott Williams \& Wilkins; 2011:372-400.

2. Yin T, Miyata T. Pharmacogenomics of clopidogrel: evidence and perspectives. Thromb Res. 2011;128:307-316.

3. Nguyen TA, Diodati JG, Pharand C. Resistance to clopidogrel: a review of the evidence. J Am Coll Cardiol. 2005;45:1157-1164

4. Tello-Montoliu A, Ueno M, Angiolillo DJ. Antiplatelet drug therapy: role of pharmacodynamic and genetic testing. Future Cardiol. 2011;7:381-402.

5. Hollenberg PF. Characteristics and common properties of inhibitors, inducers, and activators of CYP enzymes. Drug Metab Rev. 2002;34:17-35.

6. Terpening C. Clopidogrel: a pharmacogenomic perspective on its use in coronary artery disease. Clin Med Insights Cardiol. 2010;4:117-128.

7. Ancrenaz V, Daali Y, Fontana P, et al. Impact of genetic polymorphisms and drugdrug interactions on clopidogrel and prasugrel response variability. Curr Drug Metab. 2010;11:667-677.

8. Bhatt DL, Scheiman J, Abraham NS, et al. ACCF/ACG/AHA 2008 expert consensus document on reducing the gastrointestinal risks of antiplatelet therapy and NSAID use: a report of the American College of Cardiology Foundation Task Force on Clinical Expert Consensus Documents. J Am Coll Cardiol. 2008;52:1502-1517.

9. Angiolillo DJ, Gibson CM, Cheng S, et al. Differential effects of omeprazole and pantoprazole on the pharmacodynamics and pharmacokinetics of clopidogre in healthy subjects: randomized, placebo-controlled, crossover comparison studies. Clin Pharmacol Ther. 2011;89:65-74.

10. Paris B, Yerino P, Ogilvie B, Parkinson A. Abstract 130: the proton pump inhibitor (PPIs) omeprazole and rabeprazole but not lansoprazole and pantoprazole are in vitro time-dependent inhibitors of CYP2C19. Drug Metab Rev. 2008;40:89-90.

11. Fda.gov [homepage on the Internet]. US Food and Drug Administration. Information for Healthcare Professionals: Update to the Labeling of Clopidogrel Bisulfate (Marketed as Plavix) to Alert Healthcare Professionals About a Drug Interaction with Omeprazole (Marketed as Prilosec and Prilosec OTC). Available from, http://www. fda.gov/Drugs/DrugSafety/PostmarketDrugSafetyInformationforPatientsandPro viders/DrugSafetyInformationforHeathcareProfessionals/ucm190787.htm; 2009 [Last updated 2009 Nov 17; cited 2012 Dec 30].
12. Blume H, Donath F, Warnke A, Schug BS. Pharmacokinetic drug interaction profiles of proton pump inhibitors. Drug Saf. 2006;29:769-784.

13. Siller-Matula JM, Lang I, Christ G, Jilma B. Calcium-channel blockers reduce the antiplatelet effect of clopidogrel. J Am Coll Cardiol. 2008;52:1557-1563.

14. Gremmel T, Steiner S, Seidinger D, Koppensteiner R, Panzer S, Kopp CW. Calciumchannel blockers decrease clopidogrel-mediated platelet inhibition. Heart. 2010;96:186-189.

15. Good CW, Steinhubl SR, Brennan DM, Lincoff AM, Topol EJ, Berger PB. Is there a clinically significant interaction between calcium channel antagonists and clopidogrel?: results from the Clopidogrel for the Reduction of Events During Observation (CREDO) trial. Circ Cardiovasc Interv. 2012;5:77-81.

16. Schmidt M, Johansen MB, Robertson DJ, et al. Use of clopidogrel and calcium channel blockers and risk of major adverse cardiovascular events. Eur I Clin Invest. 2012;42:266-274.

17. Olesen JB, Gislason GH, Charlot MG, et al. Calcium-channel blockers do not alter the clinical efficacy of clopidogrel after myocardial infarction: a nationwide cohort study. J Am Coll Cardiol. 2011:57:409-417.

18. Harmsze AM, Robijns K, van Werkum JW, et al. The use of amlodipine, but not of P-glycoprotein inhibiting calcium channel blockers is associated with clopidogrel poor-response. Thromb Haemost. 2010;103:920-925.

19. Zahno A, Brecht K, Bodmer M, Bur D, Tsakiris DA, Krähenbühl S. Effects of drug interactions on biotransformation and antiplatelet effect of clopidogrel in vitro. Br J Pharmacol. 2010;161:393-404.

20. Neuvonen PJ, Niemi M, Backman JT. Drug interactions with lipid-lowering drugs: mechanisms and clinical relevance. Clin Pharmacol Ther. 2006;80: 565-581.

21. Lau WC, Waskell LA, Watkins PB, et al. Atorvastatin reduces the ability of clopidogrel to inhibit platelet aggregation: a new drug-drug interaction. Circulation. 2003;107:32-37.

22. Neubauer $H$, Mügge A. Thienopyridines and statins: assessing a potential drug-drug interaction. Curr Pharm Des. 2006;12:1271-1280.

23. Saw J, Steinhubl SR, Berger PB, et al. Lack of adverse clopidogrel-atorvastatin clinical interaction from secondary analysis of a randomized, placebocontrolled clopidogrel trial. Circulation. 2003;108:921-924.

24. Wienbergen $\mathrm{H}$, Gitt AK, Schiele R, et al. Comparison of clinical benefits of clopidogrel therapy in patients with acute coronary syndromes taking atorvastatin versus other statin therapies. Am J Cardiol. 2003;92:285-288. 